\title{
11-level Cascaded H-bridge Grid-tied Inverter Interface with Solar Panels
}

\author{
Faete Filho, Yue Cao, Leon M. Tolbert \\ Electrical Engineering and Computer Science Department \\ The University of Tennessee \\ Knoxville, TN 37996-2100, USA
}

\begin{abstract}
This paper presents a single-phase 11-level (5 Hbridges) cascade multilevel DC-AC grid-tied inverter. Each inverter bridge is connected to a $200 \mathrm{~W}$ solar panel. OPAL-RT lab was used as the hardware in the loop (HIL) real-time control system platform where a Maximum Power Point Tracking (MPPT) algorithm was implemented based on the inverter output power to assure optimal operation of the inverter when connected to the power grid as well as a Phase Locked Loop (PLL) for phase and frequency match. A novel SPWM scheme is proposed in this paper to be used with the solar panels that can account for voltage profile fluctuations among the panels during the day. Simulation and experimental results are shown for voltage and current during synchronization mode and power transferring mode to validate the methodology for grid connection of renewable resources.
\end{abstract}

Keywords - multilevel converter, cascaded H-bridges, solar panel, photovoltaic, MPPT, PWM

\section{INTRODUCTION}

Because energy resources and their utilization will be a prominent issue of this century, the problems of natural resource depletion, environmental impacts, and the rising demand for new energy resources have been discussed fervently in recent years. Several forms of renewable zeropollution energy resources, including wind, solar, bio, geothermal and so forth, have gained more prominence and are being researched by many scientists and engineers [1-2].

Solar cell installations involve the use of multiple solar panels or modules, which can be connected in series or in parallel to provide the desired voltage level to the inverter. The cascaded H-bridge multilevel inverter topology requires a separate DC source for each H-bridge so that high power and/or high voltage that can result from the combination of the multiple modules in a multilevel inverter would favor this topology [3-7]. To maximize the energy harvested from each string, a maximum power point tracking (MPPT) strategy is needed. The task of finding the optimum operation point might increase the complexity and component count as the number of isolated DC sources increase. The approach chosen to deal with the number of input sources was to monitor $\mathrm{AC}$ output power parameters instead of DC input measurements [8].

Traditional multilevel inverters include cascaded H-bridge inverter, diode clamped inverter, and flying capacitors inverter. This paper focuses on the single-phase 11-level $(5 \mathrm{H}$ bridges) cascade multilevel inverter.

\section{MultileVEl InVerter AND PV InTERFACE}

An overview of the system is shown in Fig. 1. The core component of this inverter design is the four-switch combination shown in Fig. 1. By connecting the DC source to the AC output by different combinations of the four switches, $\mathrm{Q}_{11}, \mathrm{Q}_{12}, \mathrm{Q}_{13}$, and $\mathrm{Q}_{14}$, three different voltage output levels can be generated for each DC source, $+\mathrm{Vdc}, 0$, and $-\mathrm{Vdc}$. A cascade inverter with $\mathrm{N}$ input sources will provide $(2 \mathrm{~N}+1)$ levels to synthesize the AC output waveform. The DC source in the inverter comes from the PV arrays, and the switching signals come from the multicarrier sinusoidal pulse width modulation (SPWM) controller. The 11-level inverter connects five H-bridges in series and is controlled by five sets of different SPWM signals to generate a near sinusoidal waveform [9-11].

The connection to the grid is done through a variable transformer to assure that at any time the number of $\mathrm{H}$ Bridges used can be controlled, the grid voltage generated by the inverter is met and also to give more flexibility to the experiment since irradiance levels might not be enough. For that reason, an additional fixed $10 \mathrm{mH}$ inductance was added as the connection inductance for power transferring mode.

The individual solar panel output power is proportional to solar irradiance variations that occur during the day. The MPPT algorithm will work sensing the output power so no feedback from the individual panels is provided to reduce the number of sensors [12].

As can be seen in Fig. 1, the lower panels, in terms of control signals, will deliver more energy than the upper panels. In order to avoid uneven power to be drawn from the panels by the inverter, a different inverter control approach for the SPWM scheme is proposed here to be used with the solar panels that can account for the voltage profile variation of the panels that occurs during the day. The MPPT and grid synchronization algorithm are fed by output and voltage current signals to generate the gate driver signals as shown in Fig. 2. In Fig. 3 are shown the inverter and its cycle by cycle SPWM control methodology. The irradiance profile over a day changes a few orders of magnitude than a $60 \mathrm{~Hz}$ system [13]. That means that a control change action over the modulation index can be taken over a few cycles of the $60 \mathrm{~Hz}$ control system. It is desired to get the same amount of power from each string, which cannot be achieved using a conventional SPWM approach. For example, the lower panels 


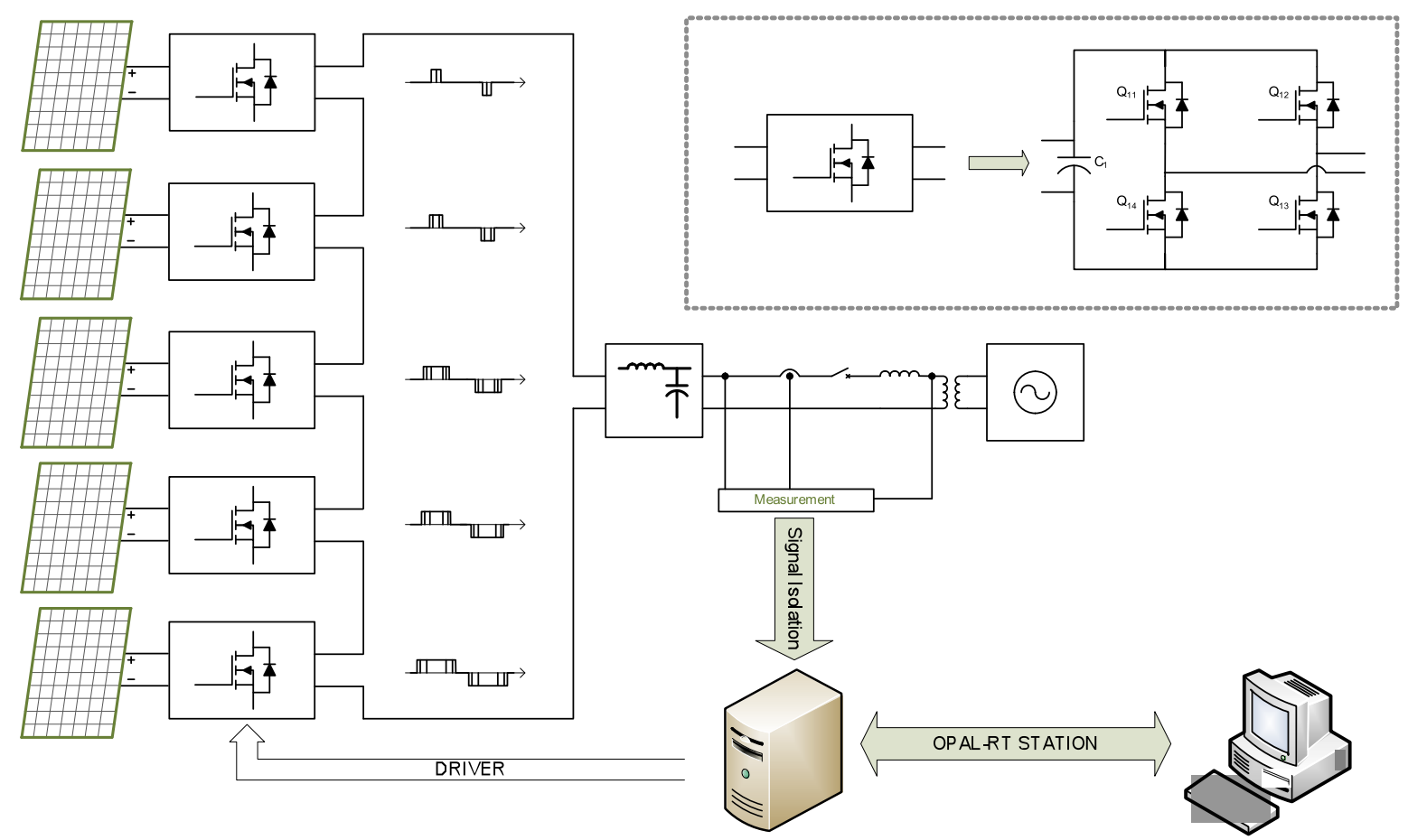

Fig. 1. Multilevel inverter system overview.

in Fig. 1 would send more power than the upper panels as they are switching for a longer time. The sinusoidal nature of the current comes as another factor that makes the power drawn from different panels uneven. The multilevel cascade topology does not require any of the H-bridges to be switched in a determined sequence as would be the case for a diode clamped multilevel (DCM) converter. This gives freedom to switch the H-bridges in the circuit in any order, which can be used as strategy to equalize the power transferred from individual panels. The control strategy implemented shifts the carrier signal over $\mathrm{N}$ cycles in the case of a $(2 \mathrm{~N}+1)$ level inverter to make it possible to draw the same amount of

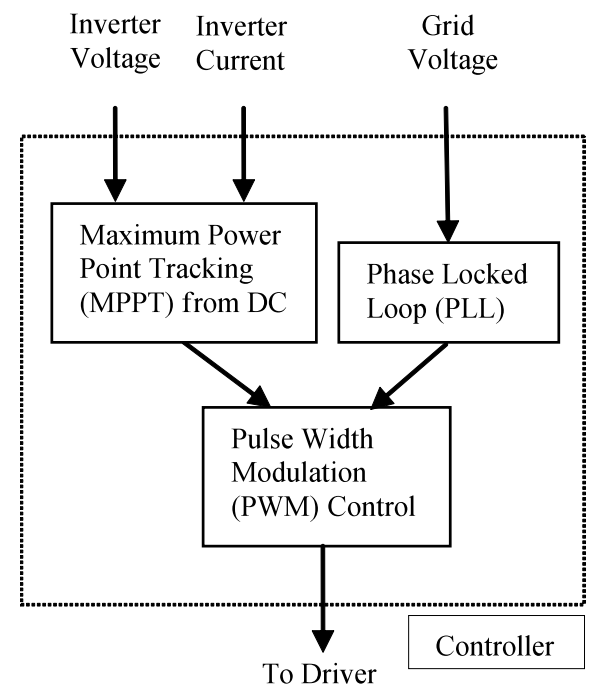

Fig. 2. Control block diagram. power from each string. Shifting the carrier down for each cycle is the same as physically changing the position of the H-bridges shown in Fig 3(a) for an 11-level inverter. In that figure five cycles of the fundamental frequency are needed to have each panel switch position with the other four. The energy stored in the capacitor will come to help in this process in a cycle-by-cycle basis to avoid a considerable voltage drop due to its considerable large capacitance (1000 $\mathrm{uF}$ ).

\section{Synchronization AND TRACKING CONTROL SyStem}

Synchronization between inverter and grid means that both will have the same phase angle, frequency and amplitude. This can be done noise proof with respect to the grid by sensing the grid voltage in a Phase Locked Loop (PLL) [1417]. Typical PLL algorithms include inverse Park-based PLL, Hilbert transformer-based PLL, and transport delay-based PLL. The one to be included in this design is the transport delay-based PLL. Fig. 4(a) shows the block diagram of the PLL algorithm. Notice that the delayed angle can be directly controlled at the computer station during the experiment to provide the signal in quadrature with the grid, which is the input to the Park transform block.

The PLL output is the actual angle position of the grid voltage. This signal is used to generate the sine wave that is used as the reference signal to the control system, which will generate the SPWM signals to drive the switches. The time required for synchronization will be dependent on the PI block parameters. Fig. 4(b) shows the PLL synchronization simulation. In that figure, the PLL starts its synchronization at 0.03 second, and it is in synchronization after about 0.13 second. Since the angle is now known, it is possible to control 


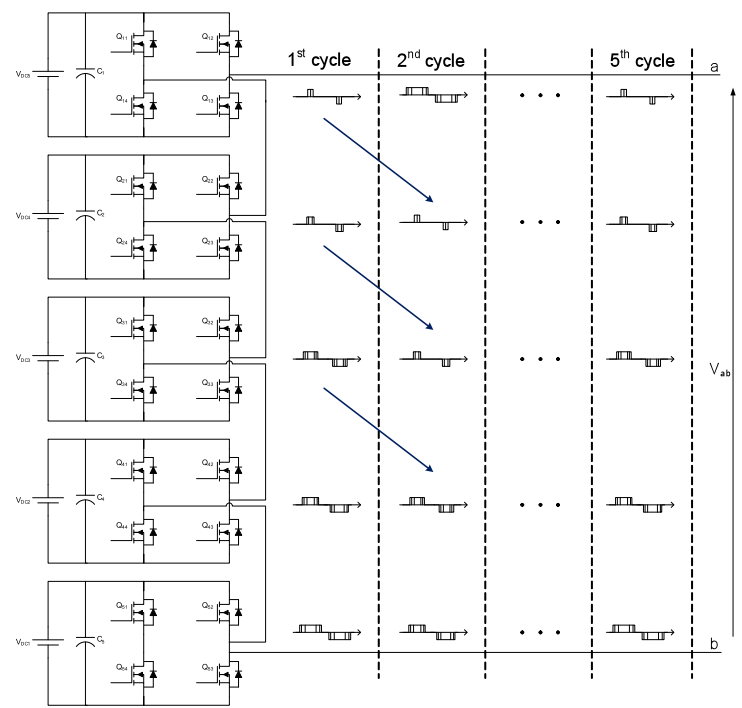

(a)

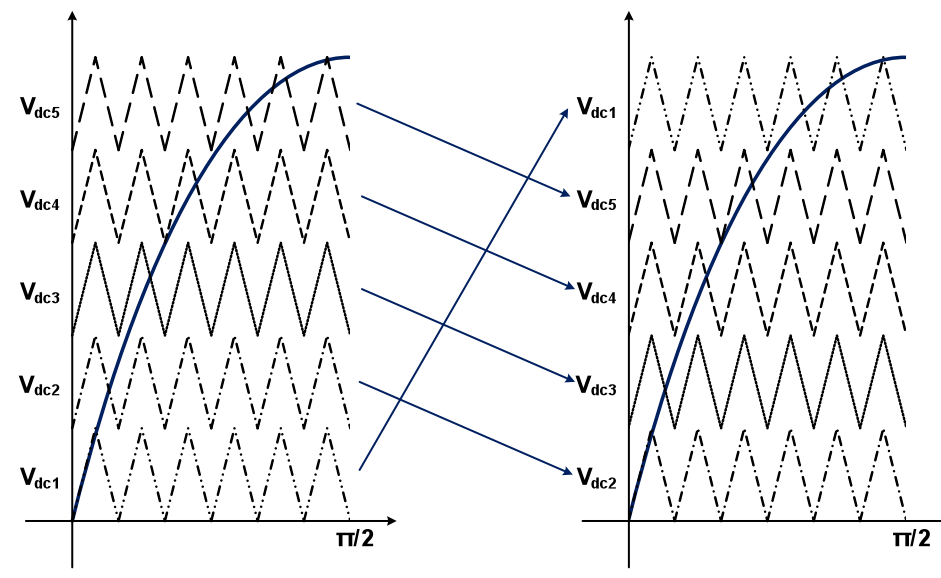

(b)

Fig. 3. (a) Inverter topology and (b) carrier shifting control scheme.

the phase difference between inverter and grid by controlling $\delta$. This allows the power flow to be controlled according to (1).

$$
P=\frac{V_{i n v} \cdot V_{g r i d}}{X_{L}} \sin \delta
$$

where $V_{i n v}$ is the inverter voltage, $V_{\text {grid }}$ is the grid voltage, $X_{L}$ is the connection impedance, and $\delta$ is the angle between grid and inverter.

Instead of sensing the individual panel voltages, the maximum power point tracking (MPPT) algorithm determines the optimal point of operation of the panel by calculating the output power and phase angle variation [18]. It monitors output voltage and current parameters by making small changes on the phase angle and looking at the power variation, as in a hill climbing optimization method to track the maximum power point.

\section{EXPERIMENTAL DEMONSTRATION}

Each one of the five H-bridges has its own $200 \mathrm{~W}$ PV panel connected as an independent source. The panels' specification can be seen in Table 1. The control signals to the bridges are sent by the OPAL-RT workstation where software and $\mathrm{I} / \mathrm{O}$ boards are installed. The system acquires grid voltage and inverter output current and voltage to the control block (OPAL-RT workstation) to generate the driver signals to the inverter. Fig. 5 shows the experimental solar panel and the multilevel inverter setup.

TABLE I. SOLAR PANEL SPECIFICATIONS

\begin{tabular}{|l|c|}
\hline \multicolumn{2}{|c|}{ Sanyo HIP-200DA3 } \\
\hline Rated Power & $200 \mathrm{~W}$ \\
\hline Maximum power voltage & $56.2 \mathrm{~V}$ \\
\hline Maximum power current & $3.56 \mathrm{~A}$ \\
\hline Open circuit voltage & $68.8 \mathrm{~V}$ \\
\hline Module efficiency & $16.5 \%$ \\
\hline
\end{tabular}

The RT-Lab control platform, which connects the software (PWM, PLL, MPPT) with the hardware (solar panel, grid, 11level cascaded H-bridge inverter), to create a real time platform, is the main tool to perform the experiments. Due to hardware limitation, the maximum achievable frequency for the SPWM signals is $2 \mathrm{kHz}$ which requires bulk filtering components as shown in Table 2. A $2 \mathrm{kHz}$ discrete-time RT-

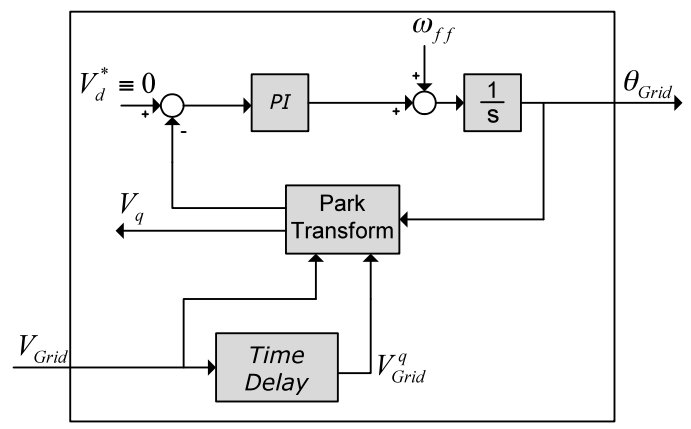

(a)
PLL ON

(b)

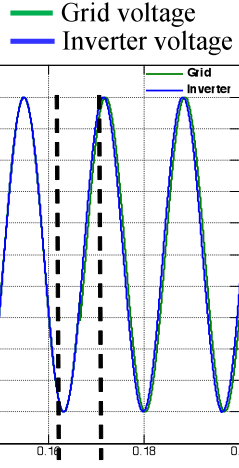

Fig. 4. (a) Transport delay-based PLL algorithm and (b) voltage synchronization using PLL. 


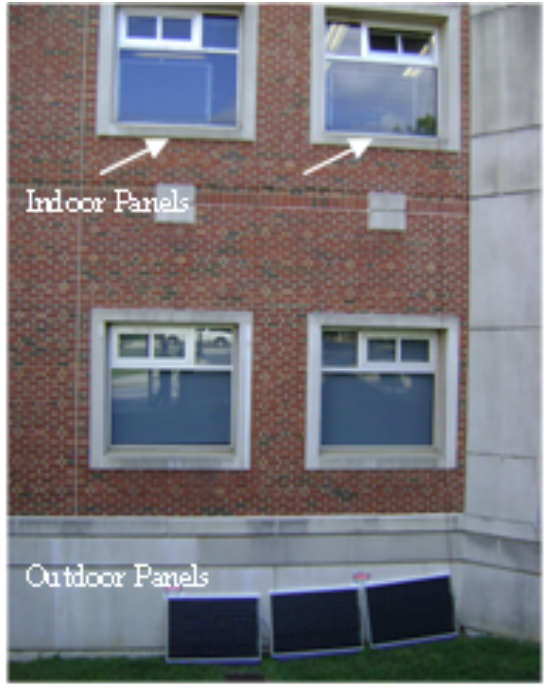

(a)

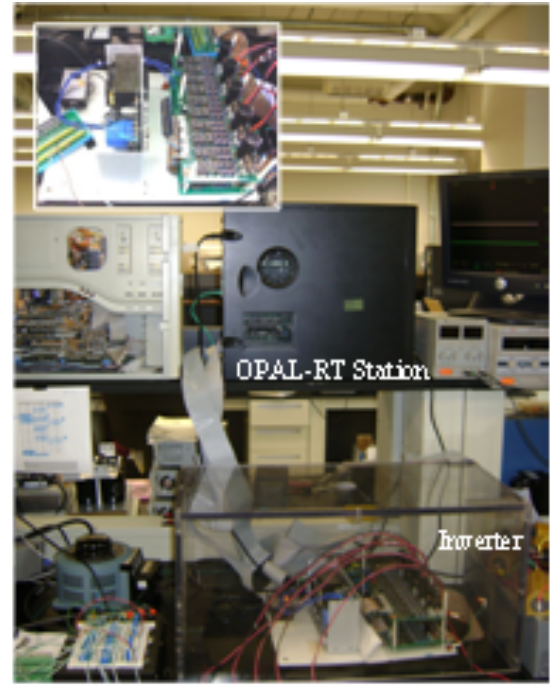

(b)

Fig. 5. (a) Solar panel arrangement and (b) experimental setup.

Lab drives the inverter with five solar panels as DC inputs and provides a waveform to interface with the $60 \mathrm{~Hz} \mathrm{AC}$ grid. Fig. 6(a) shows unfiltered inverter and filtered sinusoidal grid voltages with all five levels of H-bridge inverter under SPWM control and in synchronization. The inverter voltage was stepped up using a transformer to give more freedom during the experiments, for example, to run with all the panels working and to assure that the same amplitude was kept under cloudy conditions when the voltage drops under load condition. In Fig. 6(b), a phase shift is applied by the MPPT algorithm, and power is transmitted from the solar panels to the grid. Another case is shown in Fig. 7 with inverter output current THD shown in Fig. 7(b).

TABLE II. PASSIVE COMPONENTS SPECIFICATION

\begin{tabular}{|l|c|}
\hline Filter Inductance & $1 \mathrm{mH}$ \\
\hline Filter Capacitance & $92 \mathrm{uF}$ \\
\hline
\end{tabular}

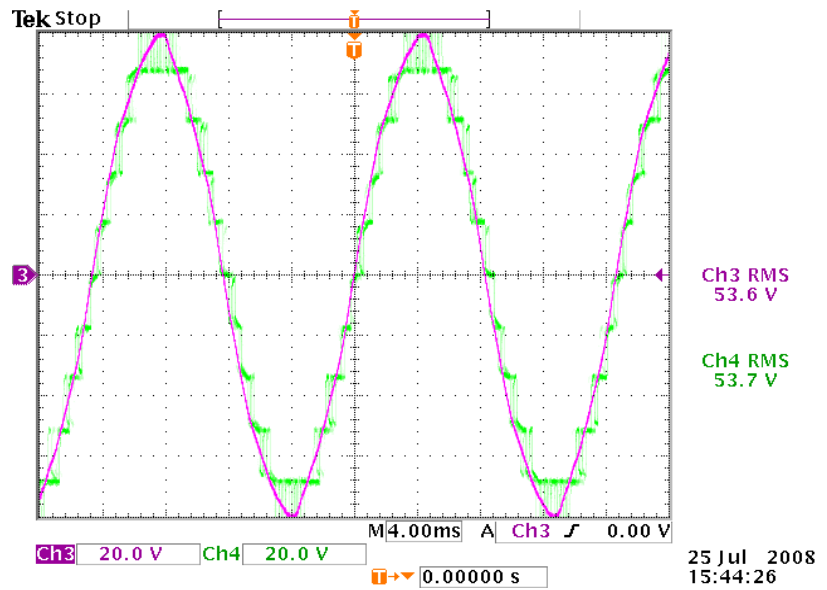

(a)

\begin{tabular}{|l|c|}
\hline Connection inductance & $10 \mathrm{mH}$ \\
\hline
\end{tabular}

\section{CONCLUSIONS}

This paper presented an eleven-level cascade H-bridge inverter, which uses PLL and MPPT with separate solar panels as DC sources to interact with the power grid. A SPWM approach was presented to deal with the uneven power transferring characteristics of the conventional SPWM modulation technique. This technique proved to be successful due to the irradiance profile and the use of capacitors to smooth the voltage fluctuation. The system was driven at 2 $\mathrm{kHz}$ because of speed constrains of the control platform, which required bulk filter components.

Grid connection results were shown using the proposed MPPT algorithm. Future work includes the use of a DSP platform to increase switching frequency and reduce filter requirements. The entire PV system structure and its interaction with the grid through PLL and MPPT algorithms

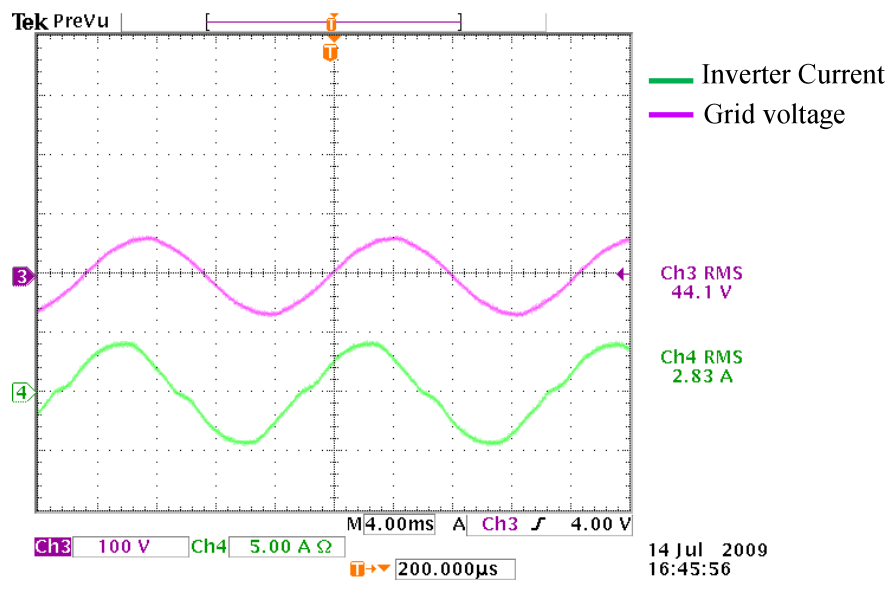

(b)

Fig. 6. Experimental voltage and current waveforms. (a) Utility voltage (purple) and unfiltered output voltage (green) and (b) voltage and current waveforms for grid connected multilevel inverter. 


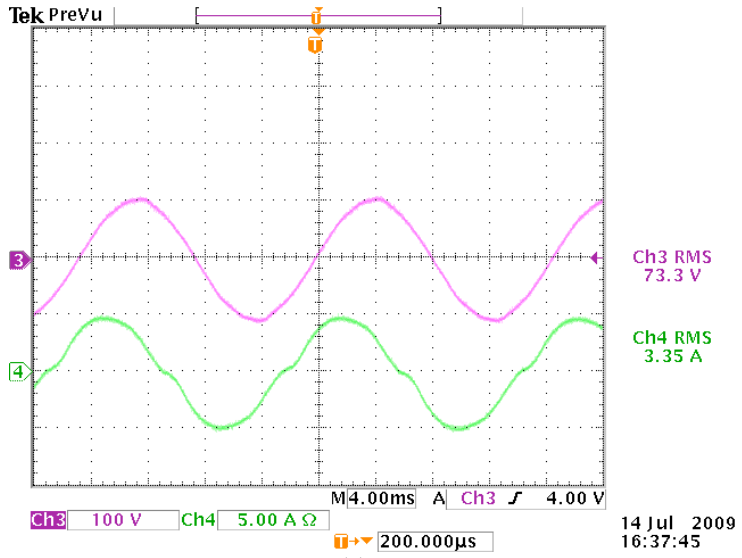

(a)

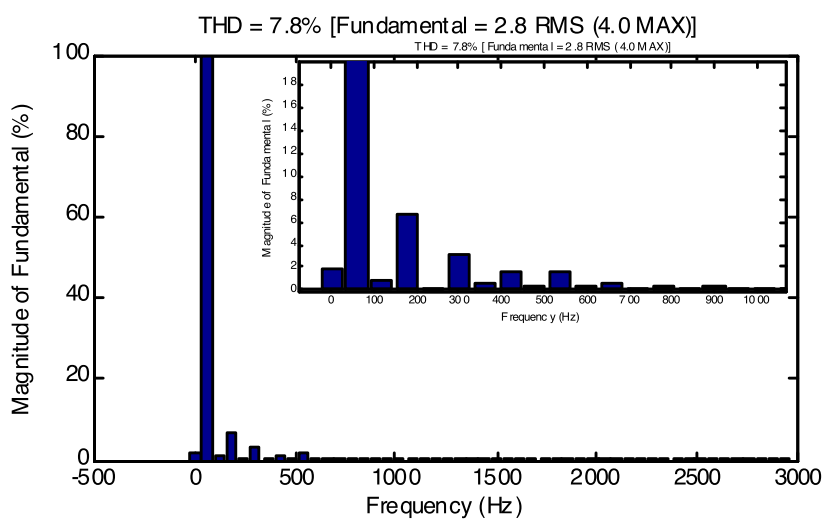

(b)

Fig. 7. (a) Grid voltage (purple) and current (green) and (b) output current THD.

were shown by the simulation and experimental results.

\section{REFERENCES}

[1] J. M. Carrasco, L. G. Franquelo, J. T. Bialasiewicz, E. Galvan, R. C. P. Guisado, Ma. A. M. Prats, J. I. Leon, N. Moreno-Alfonso, "PowerElectronic Systems for the Grid Integration of Renewable Energy Sources: A Survey," IEEE Transactions on Industrial Electronics, vol. 53, no. 4, pp. 1002-1016, June 2006.

[2] A. J. Morrison, "Global Demand Projections for Renewable Energy Resources," IEEE Canada Electrical Power Conference, 25-26 Oct. 2007, pp 537-542.

[3] J. Rodriguez, S. Bernet, Bin Wu, J. O. Pontt, S. Kouro, "Multilevel Voltage-Source-Converter Topologies for Industrial Medium-Voltage Drives, "IEEE Transactions on Industrial Electronics, vol. 54, no. 6, pp. 2930-2945, Dec. 2007.

[4] L. M. Tolbert, F. Z. Peng, "Multilevel Converters as a Utility Interface for Renewable Energy Systems," IEEE Power Engineering Society Summer Meeting, Seattle, Washington, July 15-20, 2000, pp. 12711274.

[5] S. Khomfoi, L. M. Tolbert, "Multilevel Power Converters," Power Electronics Handbook, 2nd Edition Elsevier, 2007, ISBN 978-0-12088479-7, Chapter 17, pp. 451-482.

[6] S. Busquets-Monge, J. Rocabert, P. Rodriguez, S. Alepuz, J. Bordonau, "Multilevel Diode-clamped Converter for Photovoltaic Generators with Independent Voltage Control of Each Solar Array," IEEE Transactions on Industrial Electronics, vol. 55, July 2008, pp. 2713-2723.

[7] E. Ozdemir, S. Ozdemir, L. M. Tolbert, B. Ozpineci, "Fundamental Frequency Modulated Multilevel Inverter for Three-phase Stand-alone Photovoltaic Application," IEEE Applied Power Electronics Conference and Exposition, Feb. 24-28, 2008, pp. 148-153.

[8] S. A. Khajehoddin, A. Bakhshai, P. Jain, "The Application of the Cascaded Multilevel Converters in Grid Connected Photovoltaic Systems," IEEE Canada Electrical Power Conference, 25-26 Oct. 2007, pp. 296-301.

[9] S. Ozdemir, E. Ozdemir, L. M. Tolbert, S. Khomfoi, "Elimination of Harmonics in a Five-level Diode-clamped Multilevel Inverter Using
Fundamental Modulation," International Conference on Power Electronics and Drive Systems, Nov. 27-30, 2007, pp. 850-854.

[10] J. S. Lai, F. Z. Peng, "Multilevel Converters - A New Breed of Power Converters," IEEE Transactions on Industry Applications, vol. 32, no. 3, May/Jun. 1996, pp. 509-517.

[11] B. Kavidha, K. Rajambal, "Transformerless Cascaded Inverter Topology for Photovoltaic Applications," India International Conference on Power Electronics, Chennai, India, Dec. 19-21, 2006, pp. 328-331.

[12] O. Alonso, P. Sanchis, E. Gubia, L. Marroyo, "Cascaded H-bridge Multilevel Converter for Grid Connected Photovoltaic Generators with Independent Maximum Power Point Tracking of each Solar Array," IEEE Power Electronics Specialist Conference, 15-19 June 2003, pp. 731-735.

[13] A. Abete, R. Napoli, F. Spertino, "A Simulation Procedure to Predict the Monthly Energy Supplied by Grid Connected PV Systems," Photovoltaic Eneroy Conversion, 2003. Proceedings of 3rd World Conference on, vol. 3, 12-16 May 2003, pp. 2427-2430.

[14] E. Villanueva, P. Correa, J. Rodriguez, "Control of a Single Phase Hbridge Multilevel Inverter for Grid-connected PV Applications," Power Electronics and Motion Control Conference, Poznan, Poland, Sept. 1-3, 2008, pp. 451-455.

[15] R. B. Godoy, H. Z. Maia, F. J. T. Filho, L. G. Junior, J. O. P. Pinto, G. S. Tatibana, "Design and Implementation of a Utility Interactive Converter for Small Distributed Generation," IEEE Industry Applications Conference, Oct. 8-12, 2006, pp. 1032-1038.

[16] S. M. Silva, B. M. Lopes, B. J. C. Filho, R. P. Campana, W. C. Boaventura, "Performance Evaluation of PLL Algorithms for Singlephase Grid-connected Systems," IEEE Industry Applications Society Annual Meeting, Seattle, Washington, October 3-7, 2004, pp. 22592263.

[17] A. Pandey, N. Dasgupta, A. K. Mukerjee, "A Simple Single-sensor MPPT Solution," IEEE Transactions on Power Electronics, vol. 22, no. 2, March 2007, pp. 698-700.

[18] T. Esram, P. L. Chapman, "Comparison of Photovoltaic Array Maximum Power Point Tracking Techniques," IEEE Transactions on Energy Conversion, vol. 22, no. 2, June 2007, pp. 439-449. 